\title{
Evaluation of Road Traffic Vulnerability in Urban Agglomerations Based on Entropy Weight-TOPSIS Model
}

\author{
Chengbing $\mathrm{Li}^{1, \mathrm{a}}$, Luyao Wang ${ }^{2}$ \\ 1 Transportation Institute, Inner Mongolia University, Hohhot 010021, China \\ 2 School of Traffic and Transportation, Beijing Jiaotong University, Beijing 100044, China
}

\begin{abstract}
Aiming at the problem of increasing road traffic vulnerability in urban agglomerations year by year, this paper proposes a practice-oriented model and method. Firstly, the index system of urban agglomeration road traffic is established on the basis of analyzing and sorting out relevant planning and design indexes at home and abroad. Secondly, based on principle, an evaluation model of urban agglomeration road traffic vulnerability based on entropy weight- model was constructed. Finally, an empirical study was conducted to calculate the indexes with software, and the corresponding indexes were put into the model for calculation. By comparing the calculated results with the grade classification standard, the vulnerability of the urban agglomeration and the corresponding urban road traffic was judged and the corresponding improvement Suggestions were put forward.
\end{abstract}

\section{Foreword}

So far, urban agglomeration road traffic vulnerability has studied by some of the domestic and foreign scholars. Junmei Wang has evaluated the road traffic emergency response capability at the perspective of vulnerability when it faced with sudden events [1]. European scholar named Jenelius and other authors determined the vulnerability of road sections in terms of emergency capacity assessment by constantly removing single road section until certain paths or road networks became unconnected [2]. There have been many researches on the application of methods in the field of transportation. Xinxin Yan and other authors evaluated the coordination between slow traffic and urban design [3]. Chai Li and other authors studied the optimization of alternative schemes for environmental impact of traffic planning based on method [4]. Wenbin Luo and other authors evaluated and studied the coordination between Hangzhou's urban tourism and urban development by using method [5]. Ying Wang and other authors evaluated four optional schemes of Xi'an rail transit network by combining model, AHP method and entropy weight method, and then the optimal solution is selected [6].

In a word, most domestic and foreign scholars have applied method to the research on the vulnerability of a single city, but have not systematically studied the urban agglomeration. However, with the increasing significance of city clustering, taking urban agglomeration as the research object has become a trend in the field of transportation. Based on it, on the basis of building an evaluation index system of road traffic vulnerability in urban agglomeration, this study established an evaluation model of road traffic vulnerability in urban agglomeration by using the entropy weight- model to evaluate the vulnerability of road traffic in urban agglomeration.

\section{Construction of index evaluation system of road traffic vulnerability in urban agglomeration}

According to the quantifiable principle to compare and select evaluation indexes, and draw lessons from the domestic and foreign related evaluation index system, this study on the influencing factors of urban road traffic vulnerability analysis as the breakthrough point, finally construct an index evaluation system of urban road traffic vulnerability as shown in table 1 , the calculation method of the indexes in table 2 and table 3 . In the index evaluation system, the higher the value is, the better the index is called positive index, and the smaller the value is, the better the index is called negative index.

As for the factors affecting the vulnerability of road traffic system in urban agglomerations, this study explored the following indexes, as shown in table 1 .

\footnotetext{
${ }^{a}$ Corresponding author:bingbingnihao2008@126.com
} 
Table 1. Urban agglomeration traffic index evaluation system

\begin{tabular}{|c|c|c|}
\hline Variable Layer & Index & Attribute of index \\
\hline $\begin{array}{l}\text { Traffic network } \\
\text { topological index }\end{array}$ & $\begin{array}{c}\text { Node degree } \\
\text { Average path length } \\
\text { Accumulation coefficient } \\
\text { Betweenness } \\
\text { Closeness } \\
\text { K-Core }\end{array}$ & $\begin{array}{l}\text { positive } \\
\text { negative } \\
\text { positive } \\
\text { positive } \\
\text { negative } \\
\text { positive }\end{array}$ \\
\hline $\begin{array}{l}\text { Index to measure } \\
\text { vulnerability }\end{array}$ & $\begin{array}{c}\text { Node efficiency } \\
\text { Network efficiency } \\
\text { Maximal connected subgraph } \\
\text { Relative importance of section } \\
\text { Congestion density } \\
\text { An index of the effect of flow on capacity }\end{array}$ & $\begin{array}{l}\text { negative } \\
\text { positive } \\
\text { negative } \\
\text { positive } \\
\text { negative } \\
\text { positive }\end{array}$ \\
\hline
\end{tabular}

Table 2. Positive indexes and its calculation methods

\begin{tabular}{|c|c|c|}
\hline The name of the indexes & Calculation formula & Meaning \\
\hline Node degree & $k_{i}=\sum_{j \in n} a_{i j}$ & $\begin{array}{l}k_{i} \text { is node degree, represents the } \\
\text { number of nodes } v_{i} \text { connects to }\end{array}$ \\
\hline Accumulation coefficient & $C_{i}=\frac{e_{i}}{\frac{1}{2} m_{i}\left(m_{i}-1\right)}$ & $\begin{array}{c}m_{i} \text { is the number of adjacency } \\
\text { nodes of }{ }^{v_{i}} ; e_{i} \text { represents the } \\
\text { practical edge number of adjacency } \\
\text { nodes; }{ }^{C_{j}} \text { is Accumulation } \\
\text { coefficient }\end{array}$ \\
\hline Betweenness & $B_{i}=\sum_{j, k \in n, j \neq k} \frac{\delta_{i k}(i)}{\delta_{i k}}$ & $\begin{array}{c}\delta_{j k} \text { represents the number of the } \\
\text { shortest path between } v_{j} \text { and } \\
v_{k}, \delta_{j k}(j k) \text { represents the } \\
\text { number of the shortest path } \\
\text { between } v_{j} \text { and } v_{k} \text { that passed } \\
v_{i} ; B_{i} \text { represents } v_{i} \text { 's } \\
\text { betweenness }\end{array}$ \\
\hline Network efficiency & $E=\frac{1}{n-1} \sum_{i \neq j} \varepsilon_{i j}=\frac{1}{n-1} \sum_{i \neq j} \frac{1}{d_{i j}}$ & $\begin{array}{l}n \text { is the number nodes in the } \\
\text { network; } d_{i j} \text { is the distance } \\
\text { between two nodes }\end{array}$ \\
\hline K-Core & $y=\arg \max _{c_{j}} \sum_{x_{j} \in N_{k}(x)} I\left(y_{i}=c_{j}\right) T=\left(x_{1}, y_{1}\right),\left(x_{2}, y_{2}\right), \ldots,\left(x_{N}, y_{N}\right)$ & $\begin{array}{l}x_{i}, y_{j} \text { are eigenvectors, } I \text { is } \\
\text { index function, when } y_{i}=c_{j}, I \\
\text { is } 1, \text { otherwise, } I \text { is } 0 ; N_{k} \text { is } \\
\text { the k points closest to } x \text { found in } \\
\text { the set } T \text { of all nodes }\end{array}$ \\
\hline $\begin{array}{l}\text { Relative importance of } \\
\text { section }\end{array}$ & $k=\frac{c_{a}}{c_{\max }}$ & $\begin{array}{c}C_{a} \text { is the capacity of section } a \\
C_{\max } \text { represents the biggest } \\
\text { capacity in the network }\end{array}$ \\
\hline $\begin{array}{l}\text { An index of the effect of flow } \\
\text { on capacity }\end{array}$ & $m=\frac{F_{a}}{c_{a}}$ & $\begin{array}{l}F_{a} \text { represents the flow of section } \\
a_{;} C_{a} \text { is the capacity of section } a\end{array}$ \\
\hline
\end{tabular}


Table 3. Positive indexes and its calculation methods

\begin{tabular}{|c|c|c|}
\hline The name of the indexes & Calculation formula & Meaning \\
\hline Average path length & $L=\frac{1}{\frac{1}{2} n(n-1)} \sum_{i \geq j} d_{i j}$ & $\begin{array}{c}n \text { is the number nodes in the } \\
\text { network; } d_{i j} \text { is the distance } \\
\text { between two nodes; } L \text { is average } \\
\text { path length }\end{array}$ \\
\hline Node efficiency & $\varepsilon_{i j}=\frac{1}{d_{i j}}$ & $\begin{array}{c}\varepsilon_{i j} \text { is Node efficiency, the } \\
\text { inverse of the distance between the } \\
\text { two nodes } d_{i j}\end{array}$ \\
\hline Closeness & $d_{i}=\frac{1}{n-1} \sum_{j \neq 1} d_{i j}$ & $\begin{array}{l}n \text { is the number nodes in the } \\
\text { network; } d_{i j} \text { is the distance } \\
\text { between two nodes }\end{array}$ \\
\hline Maximal connected subgraph & $S=\frac{N^{\prime}}{N}$ & $\begin{array}{l}N^{\prime} \text { is the number of nodes } \\
\text { contained in the maximum } \\
\text { connected subgraph when the } \\
\text { network topology changes; } N \\
\text { represents the number of nodes } \\
\text { contained in the original network }\end{array}$ \\
\hline Congestion density & $d=\frac{F_{a}}{l_{a} n_{a}}$ & $\begin{array}{c}F_{a} \text { represents the flow of section } \\
a ; n_{a} \text { represents the number of } \\
\text { lanes on section } a ; l_{a} \text { represents } \\
\text { the length of section } a\end{array}$ \\
\hline
\end{tabular}

\section{The establishment of the process of entropy-TOPSIS model}

Step one: The original matrix of the entropy-TOPSIS model is shown as follow: the urban agglomeration has $m$ cities called $S_{1}, S_{2}, \ldots, S_{m}$, every city has indexes $C_{1}, C_{2}, \ldots, C_{n}$ 。 $a_{i j}$ represents the number of the city $i$ 's index $j i=1,2 \ldots m ; j=1,2, \ldots 12 .{ }^{w_{j}}$ represents the weight of index $C_{j}$.

Step two: The index matrix of the original urban agglomeration is processed and the normalization matrix is obtained through calculation.

Step three: Considering the weight of road traffic vulnerability evaluation indexes of urban agglomerations, among them, $i=1,2 \ldots m ; j=1,2, \ldots 12$

The method to calculate index weight $w_{j}$ is as follows:

(1)Development of judgment matrix: When studying an urban agglomeration, $\mathrm{m}$ cities are evaluated, including 12 evaluation indexes, the corresponding index value is $a_{i j}(i=1,2 \ldots m ; j=1,2, \ldots 12)$, the judgment matrix is $R=\left(a_{i j}\right)_{m * 12}$.
(2)Standardized processing: The above judgment matrix is standardized to obtain the standardized judgment matrix $D=\left(d_{i j}\right)_{m^{* 12}}(i=1,2 \ldots m ; j=1,2, \ldots 12)$

For positive indexes, the calculation formula is shown in (1):

$$
d_{i j}=\frac{a_{i j}-a_{\min }}{a_{\max }-a_{\min }},(i=1,2 \ldots m ; j=1,2, \ldots 12)
$$

For negative indexes, the calculation formula is shown in $(2)$ :

$$
d_{i j}=\frac{a_{\max }-a_{i j}}{a_{\max }-a_{\min }},(i=1,2 \ldots m ; j=1,2, \ldots 12)
$$

$a_{i j}$ is the value of index $j$ of city $i, a_{\min }$ is the minimum value of the index ${ }^{j}$ of the city $i, a_{\max }$ is the maximum value of the index $j$ of the city $i$, that is, $x_{\max }=\max \left(x_{j}\right), x_{\min }=\min \left(x_{j}\right)$

(3)The information entropy of index $\mathrm{j}$ in the evaluation index system road traffic vulnerability in urban agglomeration is calculated, the calculation formula of index entropy is shown in (3): 


$$
e_{j}=-\frac{1}{\ln m} \sum_{i=1}^{m} \frac{1+d_{i j}}{\sum_{i=1}^{m}\left(d_{i j+1}\right)} \ln \frac{1+d_{i j}}{\sum_{i=1}^{m}\left(d_{i j+1}\right)}
$$

(4)The formula for calculating the index entropy is $\left(\sum w_{j}=1\right)$, the calculation formula is shown in (4) :

$$
w_{j}=\frac{1+e_{j}}{6-\sum_{j=1}^{16} e_{j}}
$$

Step four: Determine the various indexes of the evaluation index system of positive ideal $c^{+}$solution and negative ideal solution $c^{-}$:

$$
\begin{gathered}
c^{+}=\left\{\begin{array}{l}
\max \left\{c_{11}, c_{12}, \ldots, c_{m 12}\right\}, \text { positive index } \\
\min \left\{c_{11}, c_{12}, \ldots, c_{m 12}\right\}, \text { negative index }
\end{array},\right. \\
c^{-}=\left\{\begin{array}{l}
\max \left\{c_{11}, c_{12}, \ldots, c_{m 12}\right\}, \text { positive index } \\
\min \left\{c_{11}, c_{12}, \ldots, c_{m 12}\right\}, \text { negative index }
\end{array}\right.
\end{gathered}
$$

Thus forming the optimal scheme $c^{+}=\max \left(c_{1}^{+}, c_{2}^{+}, \ldots, c_{112}^{+}\right)$and the worst scheme $c^{-}=\max \left(c_{1}^{-}, c_{2}^{-}, \ldots, c_{12}^{-}\right)$

Step five: Calculate the distance between the most vulnerable and the least vulnerable cities in each urban agglomeration, the calculation formula is shown in (5):

$$
d_{i}^{+}=\sqrt{\sum_{j=1}^{7}\left(c_{i j}-c_{j}^{+}\right)^{2}} ; d_{i}^{-}=\sqrt{\sum_{j=1}^{7}\left(c_{i j}-c_{j}^{-}\right)^{2}}
$$

Step six: Calculate closeness degree: ${ }^{j}{ }_{i}^{j}$ Represents the relative closeness between the index factor and the ideal solution under the criterion ${ }^{j}$ of the city $i$, the formula for calculating $\tau_{i}^{j}$ is shown in (6):

$$
\tau_{i}^{j}=\frac{d_{i}^{-}}{d_{i}^{-}+d_{i}^{+}}, i=1,2, \ldots, m ; j=1,2, \ldots, 12
$$

In this study, the vulnerability status of road traffic emergency carriers is divided into five levels, as shown in table 4:

Table 4. Classification of vulnerability levels

\begin{tabular}{|c|c|c|c|c|c|}
\hline $\begin{array}{c}\text { Vulnerabilit } \\
\text { y index }\end{array}$ & $\begin{array}{c}0.8 \sim \\
1\end{array}$ & $\begin{array}{c}0.6 \sim 0 . \\
8\end{array}$ & $0.4 \sim 0.6$ & $\begin{array}{c}0.2 \sim 0 . \\
4\end{array}$ & $\begin{array}{c}0 \sim 0 . \\
2\end{array}$ \\
\hline $\begin{array}{c}\text { Vulnerabilit } \\
\text { y level }\end{array}$ & $\begin{array}{c}\text { quite } \\
\text { high }\end{array}$ & high & $\begin{array}{c}\text { Relativel } \\
\text { y high }\end{array}$ & low & $\begin{array}{c}\text { very } \\
\text { low }\end{array}$ \\
\hline
\end{tabular}

\section{A empirical study on the urban agglomeration of Hohhot, Baotou, Ordos and Yulin}

\subsection{Acquisition of data of vulnerability assessment index system of road traffic in urban agglomeration}

In this study, the urban agglomeration of Hohhot, Baotou, Ordos and Yulin was selected as the research object for case study. Figure 1 shows the road connection profile of the urban agglomeration of Hohhot, Baotou, Ordos and Yulin by using software. Each station is taken as a node, and the figure is used to calculate the 12 indexes by combining data and formula.

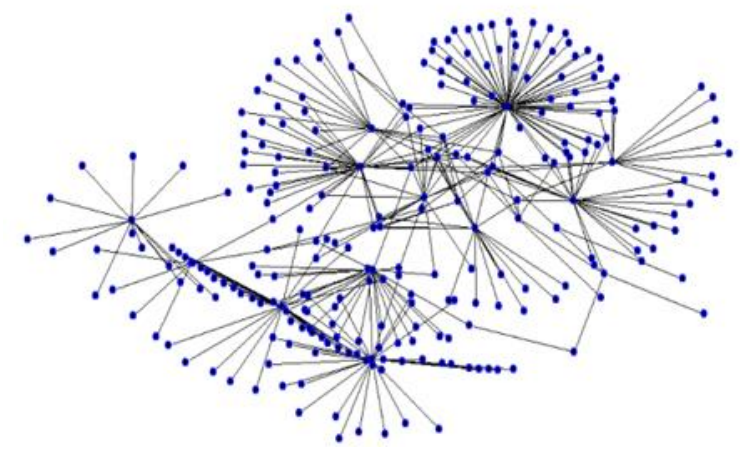

Figure 1 Road condition connection map of urban agglomeration

Pajek software was used to calculate these data by substituting the relevant formula in 1 , and 9 relevant indexes including positive index and negative index were calculated respectively. The results are shown in table 5 and table 6 .

Table 5. The negative index of urban agglomerations

\begin{tabular}{|c|c|c|c|c|c|}
\hline $\begin{array}{c}\text { Name } \\
\text { of the } \\
\text { city }\end{array}$ & $\begin{array}{c}\text { Closene } \\
\text { ss }\end{array}$ & $\begin{array}{c}\text { Avera } \\
\text { ge } \\
\text { path } \\
\text { length }\end{array}$ & $\begin{array}{c}\text { Node } \\
\text { efficien } \\
\text { cy }\end{array}$ & $\begin{array}{c}\text { Maxim } \\
\text { al } \\
\text { connect } \\
\text { ed } \\
\text { subgrap } \\
\text { h }\end{array}$ & $\begin{array}{c}\text { Congesti } \\
\text { on } \\
\text { density }\end{array}$ \\
\hline $\begin{array}{c}\text { Hohh } \\
\text { ot }\end{array}$ & 0.272 & 4.174 & 0.005 & 0.533 & 85 \\
\hline $\begin{array}{c}\text { Baoto } \\
\text { u }\end{array}$ & 0.243 & 23.167 & 0.0014 & 0.533 & 31 \\
\hline $\begin{array}{c}\text { Ordo } \\
\text { s }\end{array}$ & 0.223 & 18.169 & 0.0013 & 0.093 & 49 \\
\hline Yulin & 0.132 & 5.265 & 0.0001 & 0.099 & 67 \\
\hline
\end{tabular}

Table 6. The negative index of urban agglomerations 


\begin{tabular}{|c|c|c|c|c|c|c|c|}
\hline $\begin{array}{l}\mathrm{Na} \\
\mathrm{me}\end{array}$ & $\begin{array}{l}\text { deg } \\
\text { ree }\end{array}$ & $\begin{array}{c}\text { Accum } \\
\text { ulation } \\
\text { coeffici } \\
\text { ent }\end{array}$ & $\begin{array}{c}\text { Betwee } \\
\text { nness }\end{array}$ & $\begin{array}{c}\text { effi } \\
\text { cie } \\
\text { ncy }\end{array}$ & $\begin{array}{c}\text { K- } \\
\text { C } \\
\text { or } \\
\text { e }\end{array}$ & $\begin{array}{c}\text { impor } \\
\text { tance }\end{array}$ & $\begin{array}{c}\text { inde } \\
\mathbf{x}\end{array}$ \\
\hline $\begin{array}{c}\text { Ho } \\
\text { hho } \\
\text { t }\end{array}$ & 37 & 2.056 & 0.141 & $\begin{array}{c}0.0 \\
02\end{array}$ & 2 & 0.512 & $\begin{array}{c}0.85 \\
3\end{array}$ \\
\hline $\begin{array}{l}\text { Bao } \\
\text { tou }\end{array}$ & 16 & 0.133 & 0.042 & $\begin{array}{l}0.0 \\
02\end{array}$ & 2 & 0.572 & $\begin{array}{c}0.93 \\
3\end{array}$ \\
\hline $\begin{array}{l}\text { Or } \\
\text { dos }\end{array}$ & 18 & 0.118 & 0.044 & $\begin{array}{c}0.0 \\
009\end{array}$ & 2 & 0.625 & 0.88 \\
\hline $\begin{array}{l}\text { Yul } \\
\text { in }\end{array}$ & 33 & 0.063 & 0.016 & $\begin{array}{l}0.0 \\
07\end{array}$ & 1 & 0.641 & 0.86 \\
\hline
\end{tabular}

\subsection{The calculation process and analysis}

Step one: The original matrix of the entropy-TOPSIS model is obtained from 2.1 as follows:

$A=\left[\begin{array}{cccccccccccc}37 & 2.056 & 0.141 & 0.002 & 2 & 0.512 & 0.853 & 0.272 & 4.174 & 0.005 & 0.533 & 85 \\ 16 & 0.133 & 0.042 & 0.002 & 2 & 0.572 & 0.933 & 0.243 & 23.167 & 0.0014 & 0.533 & 31 \\ 18 & 0.118 & 0.044 & 0.0009 & 2 & 0.625 & 0.88 & 0.223 & 18.169 & 0.0013 & 0.093 & 49 \\ 33 & 0.063 & 0.016 & 0.007 & 1 & 0.641 & 0.86 & 0.132 & 5.265 & 0.0001 & 0.099 & 67\end{array}\right]$

Step two: Deal with the index matrix of the original urban agglomeration and obtain the normalized matrix through calculation as follows:

$\left[\begin{array}{llllllllllll}0.2791 & 0.0155 & 0.0003 & 0.0001 & 0.0151 & 0.0039 & 0.0064 & 0.0021 & 0.0315 & 0.0004 & 0.0042 & 0.6412\end{array}\right]$ $\begin{array}{lllllllllllll}0.2143 & 0.0018 & 0.0006 & 0.0001 & 0.0268 & 0.0077 & 0.0125 & 0.0033 & 0.3104 & 0.0002 & 0.0074 & 0.4153\end{array}$ $B=\left[\begin{array}{llllllllllll}0.219 & 0.0013 & 0.0002 & 0.0001 & 0.0224 & 0.007 & 0.0099 & 0.0025 & 0.2038 & 0.0001 & 0.001 & 0.5496 \\ 0.2019 & 0.0013 & 0.0 .45\end{array}\right]$ $\left[\begin{array}{llllllllllll}0.3053 & 0.0006 & 0.0001 & 0.0001 & 0.0093 & 0.0059 & 0.008 & 0.0012 & 0.0487 & 0.0001 & 0.0009 & 0.6199\end{array}\right]$

Step three:The weight of road traffic vulnerability assessment indexes in each urban agglomeration is considered.The original judgment matrix is: The original judgment matrix

is:

$\left[\begin{array}{llllllllllll}37 & 2.056 & 0.141 & 0.002 & 2 & 0.512 & 0.853 & 0.272 & 4.174 & 0.005 & 0.533 & 85\end{array}\right]$ $A=\left[\begin{array}{llllllllllll}16 & 0.133 & 0.042 & 0.002 & 2 & 0.572 & 0.933 & 0.243 & 23.167 & 0.0014 & 0.533 & 31\end{array}\right]$

$A=\left[\begin{array}{lllllllllllll}18 & 0.118 & 0.044 & 0.0009 & 2 & 0.625 & 0.88 & 0.223 & 18.169 & 0.0013 & 0.093 & 49\end{array}\right]$

$\left[\begin{array}{llllllllllll}33 & 0.063 & 0.016 & 0.007 & 1 & 0.641 & 0.86 & 0.132 & 5.265 & 0.0001 & 0.099 & 67\end{array}\right]$

The normalized matrix is:

$\left[\begin{array}{llllllllllll}0.4353 & 2.054 & 0.0016 & 0 & 0.0235 & 0.006 & 0.01 & 0.9968 & 0.9509 & 1 & 0.9935 & 0\end{array}\right.$ $d_{i j}=\left[\begin{array}{llllllllllll}0.5161 & 0.0043 & 0.0013 & 0.0001 & 0.0645 & 0.0184 & 0.0301 & 0.9922 & 0.2527 & 1 & 0.9822 & 0 \\ 0.3673 & 0.0024 & 0.0009 & 0 & 0.0408 & 0.01274 & 0.0179 & 0.9955 & 0.6292 & 1 & 0.9981 & 0\end{array}\right]$ $=\left[\begin{array}{llllllllllll}0.3673 & 0.0024 & 0.0009 & 0 & 0.0408 & 0.01274 & 0.0179 & 0.9955 & 0.6292 & 1 & 0.9981 & 0\end{array}\right.$ $\left[\begin{array}{llllllllllll}0.4925 & 0.0009 & 0.0003 & 0.0001 & 0.0149 & 0.0096 & 0.0128 & 0.998 & 0.9214 & 1 & 0.9985 & 0\end{array}\right]$

The weight values of positive and negative indexes in the final evaluation indexes are calculated as shown in table 7 and table 8:

Table 7. Formatting sections, subsections and subsubsections.

\begin{tabular}{|c|c|c|c|c|c|c|}
\hline $\begin{array}{c}\text { deg } \\
\text { ree }\end{array}$ & $\begin{array}{c}\text { coeffi } \\
\text { cient }\end{array}$ & $\begin{array}{c}\text { Betwee } \\
\text { nness }\end{array}$ & $\begin{array}{c}\text { Netw } \\
\text { ork } \\
\text { effici } \\
\text { ency }\end{array}$ & $\begin{array}{c}\text { K- } \\
\text { Cor } \\
\text { e }\end{array}$ & $\begin{array}{c}\text { import } \\
\text { ance }\end{array}$ & $\begin{array}{c}\text { ind } \\
\text { ex }\end{array}$ \\
\hline $\begin{array}{c}0.08 \\
34\end{array}$ & 0.092 & 0.0821 & 0.075 & 0.0 & 0.0945 & 0.0 \\
7115 \\
\hline
\end{tabular}

Table 8. Weight values of negative indexes

\begin{tabular}{|c|c|c|c|c|}
\hline $\begin{array}{c}\text { Closenes } \\
\text { s }\end{array}$ & $\begin{array}{c}\text { Averag } \\
\text { e path }\end{array}$ & $\begin{array}{c}\text { Node } \\
\text { efficienc }\end{array}$ & $\begin{array}{c}\text { Maximal } \\
\text { connecte }\end{array}$ & $\begin{array}{c}\text { Congestio } \\
\text { n density }\end{array}$ \\
\hline
\end{tabular}

\begin{tabular}{|l|c|c|c|c|}
\hline & length & $\mathbf{y}$ & $\begin{array}{c}\mathbf{d} \\
\text { subgrap } \\
\mathbf{h}\end{array}$ & \\
\hline 0.0834 & 0.0853 & 0.0928 & 0.0766 & 0.0918 \\
\hline
\end{tabular}

And the $c_{i j}$ is:

$\left[\begin{array}{llllllllllll}0.0233 & 0.0014 & 0 & 0 & 0.0011 & 0.0004 & 0.0005 & 0.0002 & 0.0027 & 0 & 0.0003 & 0.0589\end{array}\right]$ $\begin{array}{lllllllllllll}0.0179 & 0.0002 & 0 & 0 & 0.0019 & 0.0007 & 0.0009 & 0.0003 & 0.0265 & 0 & 0.0006 & 0.0381\end{array}$ $c_{i j}=\left[\begin{array}{lllllllllllll}0.0168 & 0.0001 & 0 & 0 & 0.0016 & 0.0007 & 0.0007 & 0.0002 & 0.0174 & 0 & 0.0001 & 0.0505 \\ 0.0255 & 0.0001 & 0 & 0 & 0.0007 & 0.0006 & 0.0006 & 0.0001 & 0.0042 & 0 & 0.0001 & 0.0569\end{array}\right.$

$\left[\begin{array}{lllllllllllll}0.0255 & 0.0001 & 0 & 0 & 0.0007 & 0.0006 & 0.0006 & 0.0001 & 0.0042 & 0 & 0.0001 & 0.0569\end{array}\right]$

Step four: Determine the various indexes of the evaluation index system of positive ideal solution $c^{+}$and negative ideal solution $c^{-}$.

$c^{+}=\left\{\begin{array}{l}\text { positive index: } 0.0233 ; 0.0179 ; 0.0168 ; 0.0255 \\ \text { negative index:0 }\end{array}\right.$

$c^{-}\left\{\begin{array}{l}\text { positive index: } 0 \\ \text { negative index: } 0.0589 ; 0.0381 ; 0.0505 ; 0.0569\end{array}\right.$

Step five: Calculate the distance between the most vulnerable and the least vulnerable cities in each urban agglomeration

The most vulnerable is: $d_{1}^{+}=\sqrt{\sum_{j=1}^{12}\left(c_{1 j}-0.0233\right)^{2}}=0.13$;

$d_{2}^{+}=0.06 ; d_{3}^{+}=0.06 ; d_{4}^{+}=0.09$

The least vulnerable is: $d_{1}^{-}=\sqrt{\sum_{j=1}^{12}\left(c_{1 j}-0.0589\right)^{2}}=0.18$;

$d_{2}^{-}=0.14 ; \quad d_{3}^{-}=0.17 ; d_{4}^{-}=0.18$

The weight values of each index and the original index data in table 7 and table 8 were substituted into the TOPSIS model, and the positive and negative ideal values and relative closeness degree of the city group were obtained through calculation, as shown in table 9 and table 10. The final calculation result is:

Table 9. Formatting sections, subsections and subsubsections.

\begin{tabular}{|l|l|l|l|l|}
\hline & Hohhot & Baotou & Ordos & Yulin \\
\hline$d^{+}$ & $\mathbf{0 . 1 3}$ & $\mathbf{0 . 0 6}$ & $\mathbf{0 . 0 6}$ & $\mathbf{0 . 0 9}$ \\
\hline$d^{-}$ & $\mathbf{0 . 1 8}$ & $\mathbf{0 . 1 4}$ & $\mathbf{0 . 1 7}$ & $\mathbf{0 . 1 8}$ \\
\hline
\end{tabular}

Step six: Calculate average closeness degree $\tau$

$$
\begin{aligned}
& \tau_{1}=\frac{0.18}{0.13+0.18}=0.58, \quad \tau_{2}=0.7, \quad \tau_{3}=0.74, \tau_{4}=0.67 \\
& \tau_{\text {avg }}=\frac{0.58+0.7+0.74+0.67}{4}=0.67
\end{aligned}
$$

According to the calculation results, for the overall urban agglomeration, the vulnerability level of the traffic management system in this research area is high, with an average degree of closeness of 0.67 . In the face of unexpected events, the loss is relatively high. The 
government should strengthen the management of the local level, to ensure that the local traffic safety, orderly, and efficient manner. To avoid the happening of the emergency, they can mobilize the broad masses of security companies to actively participate in the security of urban traffic construction. At the same time, improving the transport infrastructure, expanding the scale of construction and improving the traffic concept. For each city in the urban agglomeration, it is necessary to improve the road conditions in combination with the local actual conditions to bring more convenience to road traffic users.

\section{Conclusion}

In this study, an evaluation model of road traffic vulnerability of urban agglomeration based on entropy weight-TOPSISmodel was established. Pajek software was used to study the urban agglomeration of Hohhot, Baotou, Ordos and Yulin. The case study proved that the established index system and model were reasonable and feasible. The research results are as follows:

(1) The final judgment of the vulnerability of an urban agglomeration is the average vulnerability, so the vulnerability of the urban agglomeration is closely related to the vulnerability of each city in the urban agglomeration. If the vulnerability of the entire urban agglomeration is to be reduced, the vulnerability of each city can be reduced as the entry point.

(2) The vulnerability of urban agglomeration is closely related to the local conditions of each city. According to the evaluation index system of urban agglomeration road traffic vulnerability, the local government can analyze and improve the local road conditions from the two directions of reducing negative indexes and improving positive indexes.

(3) The construction of the evaluation model makes the formulation of the traffic planning scheme have a more profound guiding significance. In the practical application process, more comprehensive evaluation indexes should be used according to the specific situation, so that the formulation process of the traffic planning scheme can be truly scientific and strict.

\section{Acknowledgement}

We would like to acknowledge the National Natural Science Foundation of China (No. 71940010), Natural Science Foundation of Inner Mongolia Autonomous Region (No.2019MS05083) and Research Program of Science and Technology at Universities of Inner Mongolia Autonomous Region (No. NJZY19013).

\section{References}

[1]Junmei Wang. Research on Road Traffic Emergency Capability and Risk Assessment under the Perspective of Vulnerability [D]. Beijing Institute of Technology.2014.

[2]JeneliusE,Mattsson LarsGoran. Developing a methodology for road network vulnerability analysis[D].Nectar Cluster 1 Seminar, Molde University College, Molde(Norway),12th13th,2006:1-9.

[3]Xinxin Yan, Zhenzhou Yuan, Sijie Mao, Yuelin Wu. Coordination Evaluation of Non-motorized Traffic and Urban Design Based on Entropy Weight-TOPSIS Model [J]. Journal of Highway and Transportation Research and Development. 2018,35(9):3-5.

[4]Chai Li, Ying Ying, Ling xu, Shushen Zhang. Research on the Optimization of Alternative Schemes of Traffic Planning Environmental Impact Based on SD-TOPSIS[J].CHINAPOPULATION,RESOURCES AND ENVIRONMENT.2011(21):2-4.

[5]Wenbin Luo, Youjie Wang, Yizhou Wu. Research on Coordination Evaluation of Urban Tourism and Urban Development Based on TOPSIS Method [J]Tourism Tribune, 2008,23(12):13-16.

[6]Ying Wang, Kuanmin Chen, Yan Zhou. Evaluation of Rail Transit Network Based on TOPSIS model[J].Journal of Highway and Transportation Research and Development,2015,32(6):1330-135. 